\title{
Algunos aspectos del Quijote
}

Ricardo Crespo

\section{1.-MITO}

Un día, decidiendo a favor de las armas y en contra de las letras, Alonso Quijano quiso ser don Quijote. Con este acto de voluntad nace uno de los personajes más admirables de la literatura universal y nace con él la novela moderna, que no es más que la lucha del individuo como tal con el mundo circundante. Encerrarse en la conciencia de sí mismo equivale a enajenarse del mundo, a contemplarlo como un objeto exterior al sujeto de un aquí $y$ ahora no fáciles de reconciliar. La posibilidad de enfrentamiento entre esta voluntad y el mundo -es decir, lo que no es ella- se agiganta porque la realidad ya no es algo dado, absoluto, dogmático, sino lo que se puede interpretar desde el individuo, desde sus humores incluso o sus anomalías cerebrales. Y, sin embargo, lo real está ahí con una existencia propia, autónoma, y con su particular voluntad que se enfrenta a la nuestra. Asi es que si Cervantes nos habla ya con un lenguaje renacentista en esta subjetivación de lo real, en esta secularización del mundo y de la verdad, en este medir lo real por el hombre que busca modificarlo, también está señalando ya la crisis que va a agotar al hombre moderno. La primera novela nace pues, proféticamente, en la forma de una derrota.

Efectivamente, relativizar la realidad es fragmentarla en múltiples facetas insospechadas y contradictorias por las que aparecerán en la lucha, más tarde o más temprano, los objetos duros e inexpresivos que harán que el hombre una asi, a la soledad alienadora, la reificación. El tiempo ha ido agrandando este proceso y este sentimiento. En la lucha por modificar el mundo desde el criterio del individuo, en el quehacer agobiante y reiterado de probar cada uno por sí mismo la realidad a través de la experiencia que puede resultar desgarradora, en este abandono ciego a la racionalización y fe desmedida en la ciencia, los hombres modernos no han recibido menos 
descalabros que don Quijote y, como en un estado lúcido pero agónico, empiezan ya a renunciar a la aventura individual, a vivir desde el yo y para el yo. Por el momento, lo que se ofrece en el horizonte es un programa práctico a las necesidades colectivas. Es decir, una política. Lo que se necesita es una interpretación de la realidad tomada por una colectividad. En suma, un mito. La muerte de don Quijote tiene ahora para nosotros un sentido ejemplar que recogemos: sabemos que no es la derrota de la voluntad lo que nos hace morir, sino la de los mitos poderosos que excitan a la voluntad y la proyectan hacia el ideal. Como don Antonio, como el Viserey, como Sancho, incluso como Sansón Carrasco, preferimos a Alonso Quijano loco a cuerdo. Preferimos don Quijote a Alonso Quijano.

\section{2.-FUENTES}

Relacionando la literatura con circunstancias de un radio más amplio que la misma literatura y de la que ésta es una consecuencia (y ya no tanto desde la historia de las ideas como hace en El pensamiento de Cervantes), Américo Castro en su libro Hacia Cervantes nos hace ver cómo el genio del novelista español, captando admirablemente su circunstancia histórica, recogió y cristalizó de un modo perdurable en su máxima obra "los intentos de expresar la intimidad del hombre despojado de símbolos, enlaces y encarnaciones transcendentes, y expresarlas gravitando sobre la conciencia del ser individuo, sin envolturas ni sostenes" (1). Era lo que latía en el ambiente de aquel siglo XVI español. Ya antes los mismos españoles habían creado con el género picaresco aquel tipo rebelde que se enfrenta a la vida nacional tomada como una totalidad, plantando de soslayo las semillas críticas por la mirada de desvalorización con la que aprecia lo que la rodea. Viendo el mundo desde abajo, horizontalizando los valores, en una actitud retadora de anti-héroe, el pícaro muestra al mismo tiempo que su indigencia un resentimiento popular y secular, un antagonismo de clases y de castas que nunca antes había asomado asi de descarnado, si exceptuamos a la prostituta Areusa que en La Celestina elige su profesión en un acto de rebeldía, para no depender de nadie ni tener que verse obligada a estar siempre con el nombre de "señora" en los labios. Todo esto se puede entender fácilmente. Como nos recuerda Priestley, eran aquellos tiempos extremos en los que la magnificiencia más soberbia iba codo con codo con la pobreza más extrema, en los que el misticismo de los santos choca con las escenas realistas y cínicas de la vida del hampa ("epopeyas del hombre" se les ha llamado a estas obras picarescas), en los que la imaginación -extremada también hasta límites insanos por la potencialidad prometedora de las tierras descubiertas en el Nuevo Mundo- buscaba en vano desde su miseria los Potosis fabulosos.

(1) AMERICO CASTRO, Hacia Cervantes, Taurus Ediciones (Madrid, 1975), p. 218. 
Y poco más o menos por el mismo tiempo existía la "erótica" pastoril en la que el ya mencionado Américo Castro quiere ver el elemento más vital en el Qü̈ote, más vital aún que los libros de caballería. Como él nos dice, la importancia como fuente del Quijote de este tipo de relatos estriba en que en este personaje pastoril "el impulso vital brota de su alma con supensión de toda circunstancia externa" (2). Se desprende de aquí que esta forma de narración no podía presentar una visión total de la sociedad de aquel tiempo, de la realidad, puesto que los personajes nacen ya con una necesidad de evitar todo enfrentamiento con el mundo circundante, con lo social. La voluntad que tienen de vivir para sí mismos y de sí mismos es la negación de vivir con los demás. De aquí su transitar por caminos marginales, por campos solitarios, por oteros agrestes, en donde poder dar rienda suelta a sus más intimos sentimientos, "únicos espacios vitales en los que existen" (3). Este refugio en la intimidad del ser, esta suficiencia en su mundo interior, lo percibimos como consecuencia de una experiencia dolorosa con lo exterior, y de aqui que aparezca en la forma de una huida en lo espacial y de un repliegue hacia sí mismo en lo anímico. Hay, pues, una imposibilidad (de tipo amoroso) en estas vidas "pastoriles" que, como en el caso de Dorotea con don Fernando, más que mostrarnos las "tradiciones" de los enamorados, nos conducen hacia unas normas sociales de rígidas y autoritarias jerarquías donde estas imposibilidades nacen. Por ello, la violencia caprichosa y casi impune de los señores con los vasallos tiene que venirse el orden natural en las angnorisis sentimentaloides de las ventas.

Acaso Marcela sea una excepción de lo pastoril. Marcela elige su nueva vida sin ninguna presión, sólo guiada por un deseo de ser libre que debe todo a su voluntad. Tiene razón Américo Castro al tomarla como modelo para su teoría de la individualidad de la "erótica" pastoril. En ella no existe el amor ni el desengaño. Lo que busca en aquellos parajes y en aquel estado de vida es poder usar su derecho natural a ser libre, ejercitar su libre albedrio que "significa concretamente para Cervantes libertad de amar" (4). Desde el primer momento aparece descubierta en su impostura por los verdaderos pastores para quienes no es sino "aquella que se anda de hábito de pastora por estos andurriales" (5). No es asi, por contra, como se nos presenta a Dorotea. Cuando oímos a Marcela defenderse de las acusaciones de Ambrosio, tenemos la sensación de una libertad más genuina, más total para elegir su destino, no quizá con la sospecha de que su motivo es más imaginario, más li-

(2) Ibidem, op. cit., p. 219.

(3) Ibidem, op. cit., p. 218.

(4) AMERICO CASTRO, El pensamiento de Cervantes, Editorial Noguer, S. A. (Madrid, 1972), p. 338.

(5) MIGUEL DE CERVANTES, El ingenioso hidalgo don Quïote de la Mancha. Aguilar, S. A. de Ediciones (Madrid, 1960), p. 346. 
terario. No hay en ella aquel huir -en el sentido que le dábamos antes-, sino mås bien un buscar o, al menos, un quedarse abierta a las posibilidades que la vida puede ofrecer. Su decisión de convertirse en pastora es como una aventura tras la que se esconde la mítica Alcaldia que, claro, sólo puede tener existencia en ella misma, en el amplio y libre espacio de su deseo.

Es este, nos parece, el lazo más fuerte que le une con don Quijote; y nada tiene de sorprendente que el caballero -ya de por si amparador de doncellas en apuros- se apreste a defender la voluntad de la moza en contra de los que, achacándole la muerte de Grisóstomo, quieren violentarla. Pero desde esta situación nueva en la literatura, desde esta libertad que don Quijote ha conquistado para decidir su vida, para poder decir "Yo sé que soy y sé que puedo ser..." (6), otra cosa, ¿hacia dónde va nuestro hidalgo, qué dirección, qué sentido tiene este vagar al capricho de Rocinante? Sabemos que buscar la fama - de fuerte atracción en el Renacimiento-y que quiere aumentar su honra y hacer un servicio a la república (7). Pero en él esto es caminar hacia el mito, una vuelta a una visión ingenua de la vida $y$ del mundo, la nostalgia de una utop ía perdida.

\section{3.-FORMA CONTRA CONTENIDO}

En el alba de esta magna creación, ¿qué era don Quijote para Alonso Quijano? Rápidamente respondamos: un ideal, algo a lo que aspiraba. El proceso sería más o menos así: de su enajenante lectura de los numerosos casos expuestos en los libros de caballerías que se había aficionado a leer, el buen manchego iría seleccionando insensiblemente en la quietud de su villa aquellos rasgos que más le atraían de los héroes allí reflejados hasta formar con ellos una especie de arquetipo, el caballero perfecto, el más noble, valiente y esforzado. Tal vez añadiría unas variantes a la figura de Amadís, a quien tanto admiraba. Es este el método del arte idealista que, entre otras características tiene su fuente principal en la información libresca $y$ en la imaginación, y no en los detalles recogidos directamente de la experiencia. Ya Riley nos ha mostrado brillantemente cómo don Quijote (Alonso Quijano) procede como un artista en muchos momentos de la obra (8). Ahora bien, todas las virtudes que quisiera atribuirle a su creación las resumiríamos dentro de la heroicidad-suma, algo así como "de todos los héroes el más héroe". ¿Y qué hace falta esencialmente para ser héroe? Como bien ha señalado Ortega, la voluntad. Ser héroe es antes que nada querer

(6) Sbidem, op. cit., p. 270.

(7) Ibidem, op. cit., p. 231. pp. 66-72.

(8) EDWARD C. RILEY, Teorias de la novela en Cervantes, Taurus Ediciones (Madrid, 1966), 
serlo. Para el filósofo español, sólo los hombres que están decididos a no contentarse con los gestos que a través de la tradición y la costumbre les son transmitidos, son los que pueden llegar a este estado heróico (9). El conformismo no produce más que buenos ciudadanos en donde se acrisola, en el mejor de los casos, el término medio de lo dado. En cambio, el héroe busca una forma de ser que le pertenezca, única, un ensayo de la existencia que se prueba a sí misma. Pero ya sabemos que Alonso Quijano estaba más preocupado en imitar que en inventar. Su creación, pues, no solamente no es tal en el sentido lato del término, no es una creación a nilio, sino que tenía sus modelos en las novelas de caballerías. Es decir, que ni siquiera su imitar es un reflejo próximo de la realidad, sino una imposición sobre ella, una tiranía de la idea sobre los sentidos. De aquí que dos manadas de ovejas que vienen en sentidos contrarios por la polvorienta llanura puedan ser para él dos feroces ejércitos dispuestos a combatirse. Se nos dirá que tal percepción equivocada es producto de la locrira. Y así es. Comö bien ha observado Sender, a don Quijote le sobra locura para poder un héroe (10), que es a donde queríamos llegar. Don Quijote es un loco que quiere ser héroe, lo que equivale a no ser ni una cosa ni la otra. Sin embargo, ¿cuál es su locura? Confesemos que ante esta pregunta sentimos alguna confusión y no poco malestar: si dijéramos que está loco por querer implantar la justicia en el mundo, un vacío se declararía en nuestra humanidad. La confusión se mantiene. Cuando Ortega y Gasset imagina la silueta del hidalgo en las llanuras sin límites de la Mancha como un signo de interrogación abierto en el corazón de España y se pregunta, desesperado y reflexivo cómo querían los tiempos suyos, qué es lo español, está confesando esta confusión o, como él dice, "el Quïote es un equívoco" (11). Y no puede ser menos ante la desproporción que existe entre los nobles propósitos de don Quijote y los ridículos resultados que obtiene con sus acciones, ante la dimensión del fracaso.

Ocurre un extraño movimiento en nuestras almas de lectores: delante de la aventura de don Quijote sentimos lo absurdo del propósito, mas nos dolemos de los golpes del héroe y nos enfurecemos con él por haber fracasado. Todo nos parece una locura y al instante siguiente nos ilumina el alma una comprensión que surge desde fuera de la aventura misma. ¿Cómo aclarar esto? Creemos que en el proceso que va desde la idea inicial al fin previsto pasamos por alto los medios. Olvidamos la forma en la que don Quijote expresa su voluntad, olvidamos que quiere ser caballero andante en una época demasiado cínica para creer en semejantes personajes. $\mathrm{Y}$ empezamos entonces a pensar que su fracaso está justificado $y$, más aún, que es

(9) JOSE ORTEGA Y GASSET, Meditaciones sobre el Quijote, "Revista de Occidente" (Madrid, 1956), p. 121. p. 97.

(10) JOSE R. SENDER, Los noventayochos, Las Americas Publishing C., (New York, 1961),

ORTEGA Y GASSET, op. cit. 
inevitable. No es la bondad que persigue el acto lo que nos irrita, sino que tome una actitud, un ropaje anacrónico para ejecutarlo.

Todo esto está adelantado por Cervantes. Al primer golpe de espada la armadura deshusada de don Quijote se deshace en pedazos, como el traje de pastora de Marcela no resiste la primera mirada de un pastor que sepa qué es una oveja. Porque lo inadecuado de los medios empleados por don Quijote para implantar la justicia en el mundo no es algo que nos parezca así a nosotros en el siglo $\mathrm{XX}$, sino que se tenía que sentir sobre los mismos campos donde corrió libre la sangre de los Comuneros. Más tarde se volverá a ver con toda claridad, cuando don Quijote no resiste la "prueba de fuego" en Barcelona.

$Y$ es que la mirada de don Quijote es hacia atrás, nostálgica, y su oficio anacrónico, y ambos están recubiertas por el tenue polvillo de lo caduco, de lo no servible. Descubrimos así, al mismo tiempo que la voluntad del héroe, el error y la locura de su actitud. Sus antecedentes literarios más próximos no imitan a nadie: el pícaro lo es por necesidad (y no puede ser otra cosa); los nobles "pastores" imitan algo que les rodea y con lo que conviven, aunque adulterando su sentido. Sólo don Quijote, caballero andante, llega a lo grotesco y es ridículo y sumamente exótico.

$Y$, sin embargo, nadie como él toca nuestro corazón, nadie nos parece más digno de simpatía y conmiseración que este hidalgo pobre metido a caballero andante, nada estimula más nuestros nobles instintos que sus descabelladas aventuras y sus altivas y grandilocuentes palabras. $Y$ es que - hay que repetirlo - lo inadecuado aquí es la forma, el medio a través del cual quiere don Quijote dejar salir la joya ética que se filtra por los intercisios de todas sus estúpidas acciones. Lo que sobra -en un sentido figurado- es el ropaje, la apariencia, lo que nos hace reír y cubre valores eternos. Digámoslo abiertamente: es un viejo problema éste entre forma y contenido, tanto en la literatura como en la vida. Ante aquella locura de confundir carneros con ejércitos; en aquella erudición superflua con la que nombrar dos ejércitos de contendientes y sus vidas; con aquellas armas melladas y famélico jumento con las que se disponia el pobre loco a intervenir en la imaginada batalla, Sancho pregunta: "Señor, ¿qué hemos de hacer nosotros? ¿Qué? -dijo don Quijote-Favorecer y ayudar a los menesterosos y desválidos" (12). Este es el contenido.

\section{4.-REALIDAD Y LOCURA}

La controversia sobre si algo es bacía de barbero o el famosísimo y valioso yelmo de Mambrino la encontramos en el capítulo XXV de la Pri-

(12) MIGUEL DE CER VANTES, op. cit., p. 417. 
mera Parte, pero ya surgió en el XXI por vez primera y vuelve a aparecer casi al final, en los capítulos XLIV y XLV. Es un problema que se repite. Pero decimos mal: no es un problema. Es simplemente una manifestación más de la locura de don Quijote que necesita a cada instante sublimar la realidad para poder ajustarla al mundo que quiere vivir: aquel que surge en los libros de caballerías que circulan por la época y que él ha leído hasta perder el seso. Los que se repite, pues, es el tema. En cierto modo es el leit-motiv. Una vez será una bacía de barbero y otras una manada de carneros o unos molinos de viento. Cuanto más grande es el desajuste entre la realidad y la idealización de la misma (idelización siguiendo el modelo caballeresco), más obvia aparecerá su locura y más cómico el efecto que ésta produce en el lector.

$Y$ es que Cervantes está preocupado por la falta de verosimilitud (disparates) de estos libros de caballerías que se hacen pasar por historias verdaderas y violan las reglas del arte. Y quiere mostrarnos Cervantes que no existe tales yelmos de Mambrino sino mentes enloquecidas que los creen ver en las bacías de los barberos: es así como ellos componen sus historias fantásticas. Pero para lanzar el ideal (caballeresco) por la vertiente de lo cómico, Cervantes coloca junto al objeto en cuestión (ya bacía, ya batán) los sentidos sanos del labriego Sancho. Sancho, analfabeto, contra don Quijote, lector de libros de caballerías. Un utensilio prosáico y común o el preciadísimo yelmo que, según los poemas caballerescos italianos, ganó Reinaldo de Montalbán al matar al moro Mambrino.

El incidente ocurre así: "Lo que yo veo y columbro -respondió Sancho- no es sino un hombre sobre un asno, pardo como el mío, que trae sobre la cabeza una cosa que relumbra." "Pues ese es el yelmo de Mambrino", responde don Quijote y ya no necesita más confirmación. Pero Cervantes se cuida bien de evitarnos todas las dudas, pues de otro modo no habría efecto cómico: “... Y es pues que el yelmo, y el caballo y el caballero que don Quijote veía era esto: ...para lo cual venia el barbero, y traía una bacía de azofar..." (13). Ni por un momento dudamos que no sea una bacía de barbero y cuanto más afirma don Quijote lo contrario más venimos a darnos cuenta de su enfermedad. Porque su enfermedad no está en tomar alguna vez la apariencia por la realidad y parecerle un yelmo lo que no es sino bacía de barbero, sino en sostenerlo contra toda opinión contraria. No obstante, la defensa de su percepción no es de una intransigencia absoluta (algo tiene de cuerdo en su locura) y más tarde o más temprano acaba por recurrir a los famosos encantadores. Es asi como salva en in extremis su fe y, con ella, su mundo ideal. Madariaga ha señalado la lucha que consigo mismo mantiene el hidalgo manchego para sostener esta precaria y constantemente amenazada convicción ideal ante la realidad. Por ello, entiende

(13) Ibidem, op. cit., capítulo XXI. 
Madariaga que don Quijote, más que estar loco, quiere estarlo. Es esta voluntad la que eleva su locura, la que hace que su defensa de la caballería andante se mantenga pese a todas las burlas, agravios y reveses. En el inspirado ensayo de Turgueniev; donde compara al héroe español con Hamlet, entendemos cómo estos hombres excéntricos y altruistas, llenos de fe, acaban imponiendo su visión a la gente sencilla como Sancho. Son creadores de realidades.

Ya discrepamos algo con Américo Castro quien, apoyado en los problemas filosóficos de la época y en los tratadistas italianos, ve en el Quijote un tratamiento del tema de la realidad oscilante, de eco renacentista. Para él, Cervantes es el máximo exponente del Renacimiento en España y plantea el desplazamiento de la realidad del objeto al sujeto, es decir, el subjetivismo de la realidad. Pero nosotros no encontramos en la novela una controvesia filosófica de la relidad en estos términos. La realidad, en este caso, es una bacía de barbero y quien afirma lo contrario es un pobre hidalgo que ha perdido el seso, desmentido por todos los que se encuentran en la Venta y, en última instancia, por el mismo autor. $\mathrm{Si}$, en las palabras de este crítico, el verdadero humanismo "significa valoración, ensalzamiento de lo humano..., de su razón" (14), habría que preguntarse qué razón es la de don Quijote que ve gigantes donde hay molinos y yelmos legendarios donde aparecen bacías de barbero. La razón que atraviesa el Quijote es la de Cervantes, más cercana a la materialista de Sancho.

\section{5.-PERSPECTIVA}

A la vida se le puede mirar desde arriba o desde abajo, cielo e inframundo, mirada todopoderosa del Dios creador o sonrisa escéptica de Sileno. Desde cualquiera de estas vertientes, empero, nos parecerá que se desfigura, porque la única perspectiva real en el hombre es la humana, a medio camino. $\mathrm{Ni}$ distorción grotesca de la realidad ni idealizado embellecimiento. Este es el nivel que el lector recibe en el Quijote, tras un proceso de síntesis a cargo de la mano de Cervantes en el que, para repetir a Américo Castro, le tira de los pies al ideal o, para seguir a Ortega, tiene cogido por la cuerda el globo aerostático. De aquí partirán los intentos del héroe y la visión demasiado cruda y cínica que, a veces, tiene el antihéroe. En la lucidez, en ocasiones escatológica, de Sancho percibimos el envés del mundo, el lenguaje de Sileno. Y no es erróneo pensar, aunque parezca una paradoja, que estar muy vivo es hablar con la voz de los muertos. La vida del hombre es también lo que se desea y nos eleva sobre lo que es. Por ello, hay momentos en que sentimos a Sancho igual a don Quijote: Sancho sobre Clavileño y don Qui-

(14) AMERICO CASTRO, op. cit., p. 176. 
jote en la Cueva de Montesinos es una inversión de los papeles. Pero el mundo Cervantino está en el medio, a ras de tierra, en el nivel de lo humano.

A las proyecciones hacia arriba o hacia abajo de los dos personajes cervantinos es a lo que Ortega (15) ha llamado la proyección trágica y cómica de la novela. Nace aquélla cuando el héroe se aparta de la realidad bucando la idealidad, rechazando el ser por el querer ser. No hay tragedia sin voluntad, dice Ortega, y don Quijote vive trágicamente por esa voluntad de caballero andante con la que nace y le limita en no menos medida que al pícaro. ¿Dónde aparece lo cómico? Según Ortega, en creer que, con querer ser, se es ya. "Sabed, dice don Quijote en la primera aventura, que yo soy el valeroso don Quijote de la Mancha" (16). De partida ya ha alcanzado el ideal. Para él dejar de ser su voluntad es entregarse en brazos de Sileno.

Para Ortega, la realidad es el nivel de lo cómico; trágico el de la idealidad. El Quijote es una tragicomedia, un punto más alto de la realidad. Ortega es un idealista. Para nosotros la obra se desarrolla al nivel de la realidad, que es trágica y cómica a un mismo tiempo: superación de la visión de Sileno y descenso del ideal.

\section{6.-GENERO}

Aunque Madariaga afirma que toda la discusión sobre los libros de caballerías y sobre la novela ideal que tiene lugar entre el cura y el canónico "es estéticamente innecesaria y un peso muerto" y que sólo tiene interés para el erudito (17), tal opinión la sentimos como equivocada. La crítica a las novelas de caballerías que plantean estos personajes no es más que la teoría que pone en práctica la ficción misma. Es éste uno de los rasgos de la modernidad del Quijote.

Coincidiendo cura y canónigo, se expresa por ellos la más estricta conciencia crítica del autor. ¿Qué tiene, pues, Cervantes en contra de los libros de caballerías? Cervantes condena los libros de caballerías por motivos morales. Para Cervantes la poesía es algo intrínsicamente bueno, aunque puede usarse a veces con propósitos torcidos. Esta moralidad está relacionada, por un lado, con el decoro y, por otro, con la ejemplaridad: debe contener ejemplos y lecciones morales y en tono que no ofenda al recato $y$ al buen gusto. Pero, como las antiguas fábulas milésicas, desconocen los libros de caballerías la función instructiva que se relacionaba a su vez con el estilo: los libros de caballerías eran intelectualmente inaceptables e incapaces de convencer desde el punto de vista estético. La caridad requerida se oponía así a los famosos ovillados párrafos de un Feliciano Silva, por ejemplo. Cervantes condena también estos libros por ser falsos, mentirosos y absur-

(15) ORTEGA Y GASSET, op. cit.

(16) MIGUEL DE CERVANTES, op. cit., p. 262. 1872.

(17) SALVADOR DE MADARIAGA, Guia del lector del Quj̈ote, Editorial Sudamericana, 
dos, problema relacionado con los anteriores, pues se debatía en la época cómo decorar la novela con los bellos y deseables adornos del poema, sin sacrificar la estricta verosimilitud que le es esencial. Así se relacionaba la poesía con la moral, de tal modo que los tres principios forman una cadena sólidamente unida en sus eslabones: la utilidad de la prosa dependía de la verdad poética y ésta no se podía lograr sin la belleza, que era considerada una virtud moral. Por tanto, los libros de caballerías eran falsos desde el punto de vista histórico, porque jamás habian ocurrido en la realidad,y desde el punto de vista poético, porque jamás pudieron ni debieron ocurrir. La tarea del novelista era diferente a la del historiador y la verdad no podía ser tal si no era verosímil. Mas esta verosimilitud no se entendía en la época en el sentido que hoy le damos al término realismo, sino que, según expresión de Américo Castro, ese mundo de lo verosimil "podía convertirse en el paradigma del deber ser". Incluso para Aristóteles lo verosímil poético tiene más alcance que la verdad misma. Notemos que el deber ser es un principio normativo, voluntad de transformación de lo que es.

Acto seguido el canónigo pasa a proponer la novela ideal, siguiendo al Piciano y a algunos tratadistas italianos, en lo que se debe interpretar como una descripción del Persiles y Segismunda. Seguimos a Riley en el desarrollo de estas ideas (18). Es importante la variedad que, principio natural, tiene su origen en la multiplicidad de los episodios de la épica. Esta variedad tiene que incluirse en una unidad orgánica a través de someter la materia tratada a las exigencias de la invención y la verosimilitud. La invención es natural también y establece la superioridad del poeta sobre el historiador, habla de su mayor libertad, y se aviene al criterio aristotélico de dar prioridad al argumento sobre la creación de carácteres. Esta invención tiene que aproximarse a la verdad, controlar la fantasía desbordada. Aunque la naturaleza es el modelo, no hay que imitarla servilmente, puesto que el arte mejora a la naturaleza. Lo que tiene que respetar es la verosimilitud, pues la invención de lo imposible constituye el disparate (no verdad) estético. Según Américo Castro la fábula pretende imitar la realidad ideal. Finalmente, Cervantes quería hacer épica en prosa, pues Aristóteles afirmaba que la esencia de la poesía estribaba en la invención, no en que esté escrita en verso. Se propuso Cervantes combinar el atractivo de los libros de caballerías con las nobles virtudes de los poemas épicos. Es sabido que los libros de caballerías surgen de los antiguos cantares de gesta que se van prosificando y alcanzan características diametralmente opuestas.

Don Quijote no es un héroe épico; le sobra Sancho, la locura y la realidad. El Quijote es una parodia de lo épico.

Es don Quijote un individuo unidimensional; el Quijote, la primera novela moderna porque existe Sancho.

(18) EDWARD C. RILEY, en op. cit. 